\title{
DESIGN AND AEROELASTIC ASSESSMENT OF A FORWARD SWEPT WING AIRCRAFT
}

\author{
Wolf R. Krüger, Thomas Klimmek, René Liepelt, Hauke Schmidt, Stefan Waitz, Sunpeth Cumnuantip
}

\author{
Deutsches Zentrum für Luft- und Raumfahrt, Institut für Aeroelastik, Bunsenstr. 10, 37073 Göttingen, \\ Germany,Wolf.Krueger@DLR.de
}

\begin{abstract}
Aeroelastic effects strongly influence the design of an aircraft. To be able to assess those effects early on, reliable simulation models representing the global aeroelastic properties of a new design are required. At a conceptual or a pre-design stage, an intelligent parameterization concept allows for limited changes of the configuration while the simulation models are adapted accordingly. In the DLR project Integrated Green Aircraft, the goal was to investigate the impact of technologies for the reduction of fuel consumption on the aeroelastic properties of aircraft. One main aspect was the influence of laminar wing design on divergence, flutter and dynamic loads. As the reference aircraft in the project, the concept of a forward-swept wing aircraft with rear-mounted engines has been analysed. An aeroelastic model has been built up in the project. The model design procedure is based on the DLR in-house tool set MONA (ModGen/NASTRAN). Focus of this design process is the generation of a parameterized structural model, representing the global dynamic properties of the elastic aircraft, but as detailed as reasonable to capture relevant local effects and to result in a feasible structural design. In the article, the aircraft design is presented. The modelling and sizing process for the structure is described. Results of the loads analysis as well as of the aeroelastic stability analyses are discussed.
\end{abstract}

Keywords: Forward Swept Wings, Aeroelastic Design, Rear Mounted Engines, Parametric Modelling

\section{AEROELASTIC ASSESSMENT OF GREEN AIRCRAFT}

\subsection{Aeroelasticity and laminar flow wings}

In the development phase of new aircraft, fuel efficiency has always been a central issue. The use of natural laminar flow wings for transport aircraft operating at transonic speeds has been suggested as a means to increase aircraft performance. A forward-swept wing aircraft is a promising configuration for that purpose, overcoming some inherent physical limitations of maintaining laminar flow at transonic conditions. Such a configuration has a large influence on the aeroelastic properties of the aircraft.

Classis aircraft design tasks driven by aeroelastic considerations are structural sizing due to static and dynamic loads, and control surface layout. To be able to assess those effects early on reliable simulation models representing, the global aeroelastic properties of a new design are required. At a conceptual or a pre-design stage, these models need to be parameterized, so that limited changes in the configuration can still be investigated quickly.

In the DLR project Integrated Green Aircraft (iGREEN) the impact of technologies for the reduction of fuel consumption on the aeroelastic properties of aircraft has been investigated. One main aspect was the influence of laminar wing design on divergence, flutter and dynamic loads. The work packages of the project were dedicated to the following topics: the investigation of the influence of the dynamic motion of the laminar/turbulent transition point on the flutter boundary [1,2]; an extensive numerical and experimental campaign including a newly designed gust generator facility in the transonic wind tunnel Göttingen [3, 4], and studies on the influence of thrust vector motion and gyroscopic effects on flutter. Finally, relevant conclusions from all work packages were to be demonstrated on a numerical application, the design and analysis of a reference aircraft configuration.

As this reference aircraft, the concept of a forward-swept wing aircraft with rear-mounted engines and a T-Tail has been selected, see Fig. 1. The configuration with a forward-swept wing was selected due to its advantages for aerodynamic performance by maintaining laminar flow at transonic conditions. For the aerodynamic behaviour at supercritical Mach numbers, the wing sweep at mid-chord is responsible, and a higher sweep is desirable to reach higher flight speeds. However, the ability to maintain natural laminar flow is limited by the wing sweep at the leading edge due to the cross-flow instability, and a higher wing sweep is detrimental. For a conventional wing with positive sweep, the leading edge sweep is higher than the sweep at mid-chord. On the other hand, for a forward-swept wing, i.e., negative sweep, the leading edge sweep is lower than the sweep at mid-chord, thus allowing higher flight speeds while preserving natural laminar flow. This effect is well described by Seitz and 
co-authors in [5], and has been the design driver for the aircraft configuration defined in the LamAiR project, presented in [5] as well as in [6]. The operational requirements of this aircraft are comparable to a common short-to-mid-range transport aircraft, for 150 passengers and $5 \mathrm{t}$ of cargo, with a design Mach number of 0.78 (at $9,700 \mathrm{~m})$, a maximum take-off mass of $73 \mathrm{t}$, and a range of 4,815 $\mathrm{km}(2,600 \mathrm{~nm})$. The wing span is $35.8 \mathrm{~m}$, the leading edge sweep is $-17^{\circ}$, translating into a sweep of $-19.6^{\circ}$ at quarter chord. The aircraft is to be equipped with CFM56 class turbofans. Preliminary design studies in LamAiR have been undertaken with the preliminary aircraft design tool PrADO of TU Braunschweig [7]. As a complete aircraft design was beyond the scope of the iGREEN project, the LamAiR configuration was used as a basis for the iGREEN reference aircraft.

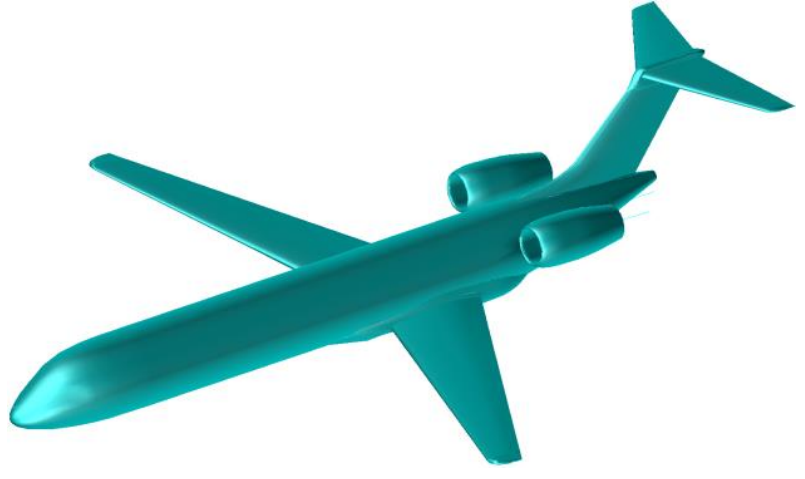

Figure 1: Geometry of the LamAiR configuration

In the iGREEN project, the aeroelastic properties of the forward-swept wing aircraft were of interest, most notably the behaviour under gusts and the influence of gust loads and divergence constraints on structural sizing. Another topic was a potential increase in control surface efficiency positively influencing manoeuvrability. Furthermore, the influence of rear-mounted engines on aeroelastic stability was of interest. In the iGREEN project, the design envelope and the aeroelastic stability envelope of the aircraft as well as the resulting flight conditions for aeroelastic and loads analysis have been defined. A parameterized global finite element model of the aircraft has been built up, and the wing and the empennage structure have been sized based on a selected number of typical load cases. Finally, aeroelastic analyses have been performed, covering divergence analyses, dynamic loads analyses, as well as a classical flutter analysis with an additional investigation of the influence of the gyroscopic effects of the engines on the flutter boundary.

\subsection{Related work}

From the aeroelastic point of view, forward-swept wings have a reputation to be prone to divergence and to increased gust loads; both might be limiting factors in structural sizing. This topic has been long known, and a standard structural design for forward-swept wings would result in higher structural weight due to the required higher stiffness when compared to a backward-swept wing. However, from the beginning of the application of composite materials for wings, it has been suggested to prescribe fibre directions such that the coupling of wing bending and torsion, responsible for the sensitivity to divergence and gust, is influenced positively (see the much cited paper by Krone [8], even though the effect is less pronounced for realistic wing topologies when compared to Krone's example). Such an intentional use of the properties of composite materials has become to be known as Aeroelastic Tailoring. A series of investigations by Weisshaar and co-authors have been performed for forward-swept wings, e.g. [9, 10], mainly connected to the X-29 programme [11]. The forward-swept wing has remained a favourite for application of improved modelling of composite structures ever since, see among others the article by Lottati [12] and the series of investigations by Librescu and co-authors, e.g., [13]. However, all studies were either driven by military configurations like the X-29 or the Russian Sukhoi Su-47 prototype, or isolated wings were regarded. To the authors' knowledge, no systematic aeroelastic investigation of a forwardswept wing transport aircraft, flying at transonic speed, has been widely published so far; much research on the iGREEN configuration has been novel in that field.

Aeroelastic Tailoring had not been a task originally defined in the iGREEN project. However, since then the work has been extended to include applications of state-of-the-art tailoring methods for the forward-swept wing configuration, described by Dillinger et al. $[14,15]$. While a thorough report of Dillinger's work is beyond the 
scope of this article, it should be noted that his tailoring approach and the subsequent aeroelastic analysis is based on shell models. In contrast to that, much of the recently published work in the community focuses on the improvement of beam models to incorporate all physical properties of complex composite structures, see for example the work of Hodges, Patil, and Cesnik [16, 17], and the recent advances of Petrolo and co-authors [18, 19].

The range of aircraft conceptual or pre-design design tools is far too wide to be covered here, but a number of approaches where aeroelastic investigations are in the focus have been developed over the years by various research groups. The next-generation conceptual aero-structural sizing (NeoCASS) programme package, originally of Politecnico di Milano, has been developed for aero-structural analysis of a design layout at a conceptual design stage. It consists of a suite of Matlab modules comprising a range of methods including computational, analytical and semi-empirical approaches, see [20, 21]. The preliminary aircraft design tool PrADO of TU Braunschweig [7] has the capability to set up models with a sufficient level of detail for aeroelastic analyses; the iGREEN configuration is based on an overall aircraft data set originally generated by PrADO. A number of analysis packages for aircraft with high aspect ratio have been developed, among them NATASHA of Georgia Institute of Technology [22], and UM/NAST of University of Michigan [23]. The DLR modelling and aeroelastic analysis process is based on the in-house development MONA, described in the sections below. It should be noted, however, that the purpose of the work described in the article was not a multidisciplinary optimization of the forward-swept aircraft configuration, but structural sizing and an extensive aeroelastic assessment of the given configuration.

Next to the forward-swept wing aircraft there are a number of unconventional configurations denoted as "UltraGreen Designs", mostly either driven by drag reduction or by weight reduction demands. Among those are the so-called Prandtl plane as proposed, among others, by Frediani [24], and the Strut-Braced transport aircraft as well as the Blended Wing Body transport aircraft, both quite comprehensively assessed in the NASA Subsonic Ultra Green Aircraft Research activity [25]. Several so-called "Pro-Green" aircraft configurations have been suggested and investigated in the European NACRE project, among them a forward-swept wing configuration for 180 passengers [26].

\subsection{Methods and tools}

For the planned aeroelastic investigations, the reference aircraft has to be designed with a structure representing realistic dynamic properties of such a configuration. The availability of appropriate structural models is a frequent requirement in projects where aeroelastic analyses are included; however, in many cases, especially early on in a design cycle, reliable finite element models are not available. For that reason, a fully parameterized finite element model generation and sizing process, MONA (ModGen and NASTRAN), has been developed in the DLR Institute of Aeroelasticity. The process is based on two major components-first, the DLR tool ModGen is used to generate the finite element model of the iGREEN configuration including the data needed for structural sizing. Second, MSC.NASTRAN is employed for sizing of the structure and subsequent analysis.

The programme ModGen has originally been developed for aeroelastic modelling of aircraft wings, and is now capable to generate full aircraft structural models. Focus of the design process is the generation of a parameterized structural model, global enough for the assessment of dynamic properties of the elastic aircraft, but detailed enough to capture important local effects and to result in a feasible structural design.

Figure 2 shows the flow of the MONA process for parametric structure modelling and conceptual aeroelastic analysis. A detailed description of ModGen capabilities and process integration can be found in [27] and [28]. The tool can be used as a stand-alone application, but also embedded in design processes as shown in DLR projects like VAMP [29] or UCAV 2010 [30]. MONA is also part of the design and analysis framework defined in the DLR project Digital-X [31], where a focus is on the interface of the aircraft design process to CFD-based loads. 


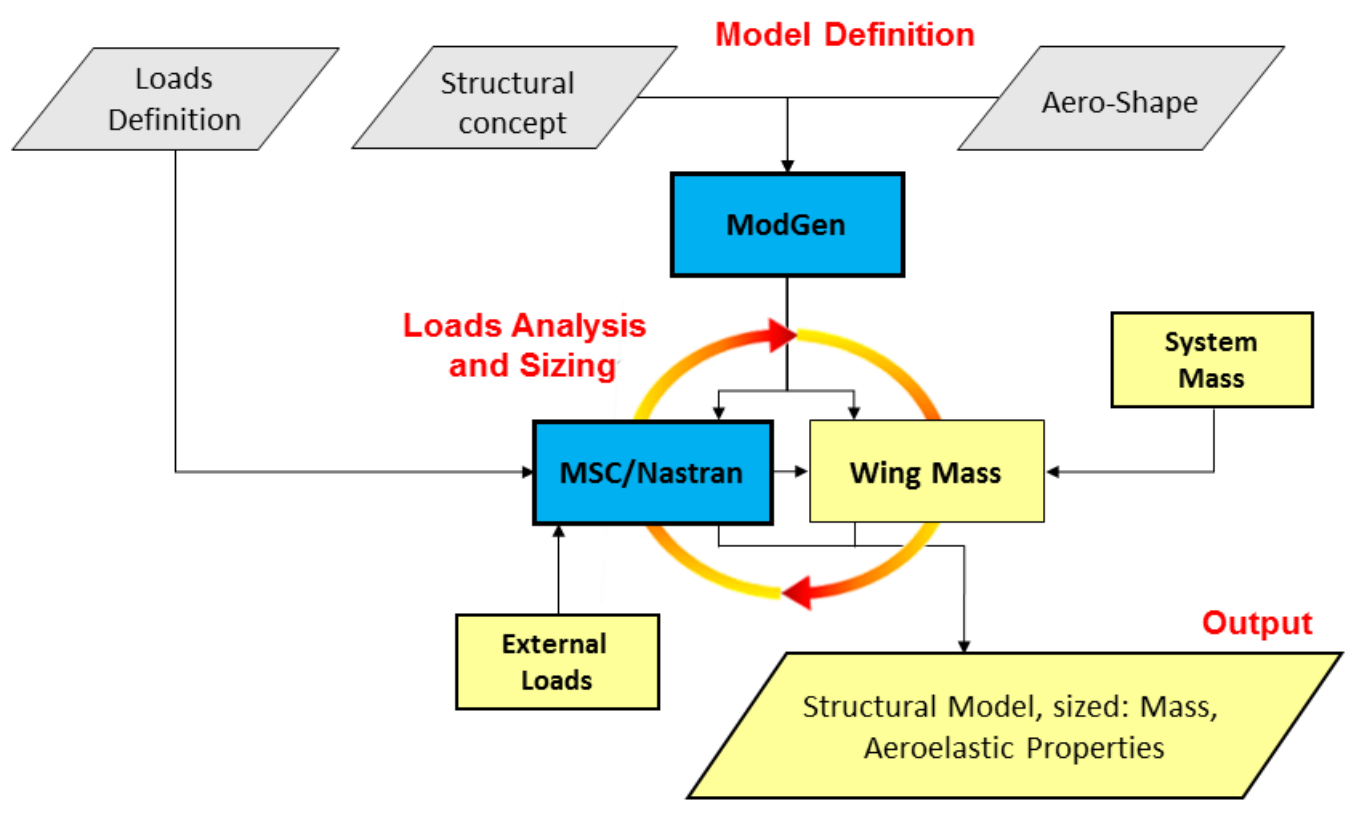

Figure 2: MONA model generation and sizing process

The model generation and sizing process starts with a defined aircraft configuration in terms of global parameters (operational parameters such as speed, altitude, and mass cases) and outer geometry. Finally, a set of load cases is the base for the sizing process.

An internal realistic structural layout and the outer shape are defined by parametric geometric objects, basically as so-called B-splines. The setup of the geometrical model is a sequential process, following common rules that are used for the design of a wing structure based on a structural wing box. By taking advantage of the analytic geometrical objects, the finite element (FE) model is then derived. Even though the philosophy of the FE setup is rather generic, output of the model generator is focused on creating elements for FE codes following the NASTRAN syntax. Further, sub-models based on the parameterized definition are generated, see Fig. 3. They include input for doublet lattice-type aerodynamics for use in MSC.NASTRAN [32] or ZAERO [33], elements for the aero-structure coupling, interface definitions for the connection of separate FE models, formulation of the optimization model, and a fuel model. Other non-structural masses, e.g., system masses, are included from external data sources. Composite materials can be modelled, but in the case of the iGREEN configuration, only isotropic material has been assumed for the structure.

Based on the obtained finite element, the aerodynamic and the coupling model, a structural optimization model is built, and a structural sizing is performed. The sizing of the structural model is done using preliminary crosssection wise sizing methods using cut loads, and the NASTRAN sizing capabilities, i.e., fully stressed design or structural optimization. For this purpose, either external loads (e.g., from CFD analysis), or loads (aerodynamic and inertia) from MSC.NASTRAN aeroelastic trim or gust analysis can be applied. The resulting FEM can then be used for further aeroelastic analysis. The modelling procedure and the sizing process for the iGREEN configuration is described in Sect. 2. 


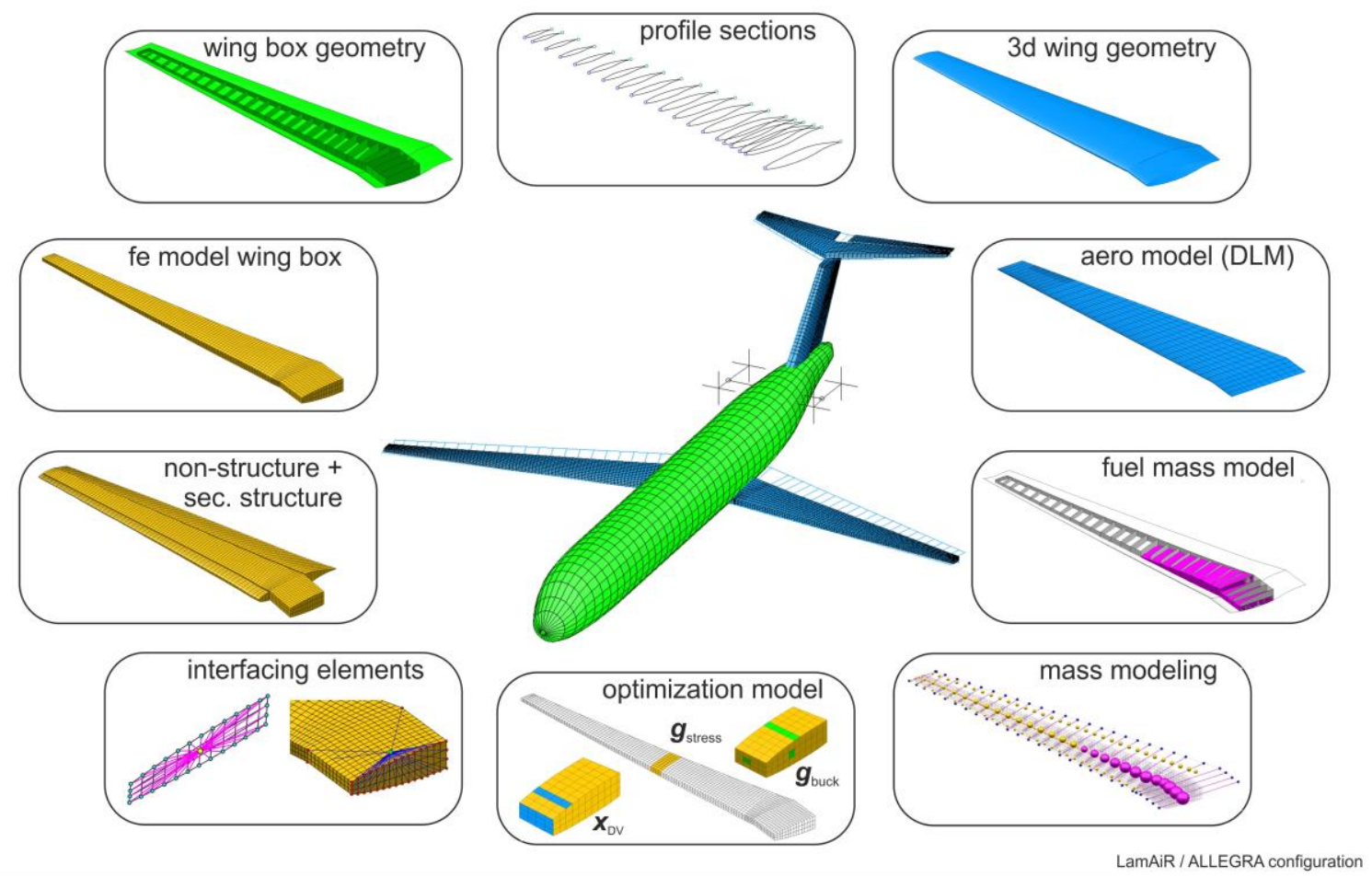

Figure 3: Disciplinary models from the parametric model generation process

\section{MODELLING OF THE IGREEN-CONFIGURATION}

\subsection{Operational requirements}

As already mentioned, the basic configuration of the iGREEN reference aircraft had been defined in the DLR project LamAiR. However, in LamAiR the focus was on the detailed design and optimization of a natural laminar flow wing, including aerodynamic optimization and design of a composite (CFRP) wing structure, while fuselage, empennage and engines were taken from a preceding preliminary design performed in the tool PrADO. For aeroelastic analyses, a full aircraft model with realistic global stiffness and mass properties has been developed, including a structural design of the wing and the empennage, a representative elastic beam model for the fuselage, and a mass model including structural mass, system mass, a fuel model and payload. Contrary to the detailed CFRP wing of LamAiR, the iGREEN variant of the aircraft is assumed to consist of an aluminium structure.

From the specification of the aircraft, described above, the design speeds have been derived. The design speeds are given in Fig. 4. The resulting flight envelope, used to select the points for loads, divergence and flutter calculations, is shown in Fig. 5.

Also from the specification, a set of mass cases used for the loads calculation and sizing process have been derived, see Fig. 6. The aircraft weight given in the table is the target weight from the PrADO pre-design loop. 


\section{VMO/MMO}

\begin{tabular}{|c|c|c|c|c|c|c|c|c|}
\hline $\mathrm{H} / \mathrm{ft}$ & $\mathrm{H} / \mathrm{m}$ & M & KCAS & KEAS & KTAS & $\begin{array}{l}v_{\text {CAS }} \\
{[\mathrm{m} / \mathrm{s}]}\end{array}$ & $\begin{array}{l}\mathrm{V}_{\text {EAS }} \\
{[\mathrm{m} / \mathrm{s}]}\end{array}$ & $\begin{array}{l}v_{\text {TAS }} \\
{[\mathrm{m} / \mathrm{s}]}\end{array}$ \\
\hline 0 & 0 & 0.529 & 349 & 349 & 349 & 179.5 & 179.5 & 179.5 \\
\hline 10000 & 3048 & 0.629 & 349 & 345 & 401 & 179.5 & 177.5 & 206.4 \\
\hline 20000 & 6096 & 0.753 & 349 & 338 & 462 & 179.5 & 173.8 & 237.9 \\
\hline 23299 & 7080 & 0.800 & 349 & 335 & 485 & 179.5 & 172.3 & 249.6 \\
\hline 41010 & 12500 & 0.800 & 255 & 254 & 459 & 131.2 & 130.8 & 236.1 \\
\hline
\end{tabular}

\section{VD/MD}

\begin{tabular}{|c|c|c|c|c|c|c|c|c|}
\hline $\mathrm{H} / \mathrm{ft}$ & $\mathrm{H} / \mathrm{m}$ & M & KCAS & KEAS & KTAS & $\begin{array}{l}\mathrm{v}_{\text {CAS }} \\
{[\mathrm{m} / \mathrm{s}]}\end{array}$ & $\begin{array}{l}V_{\text {EAS }} \\
{[\mathrm{m} / \mathrm{s}]}\end{array}$ & $\begin{array}{l}\mathrm{V}_{\mathrm{TAS}} \\
{[\mathrm{m} / \mathrm{s}]}\end{array}$ \\
\hline 0 & 0 & 0.597 & 395 & 395 & 395 & 203.2 & 203.2 & 203.2 \\
\hline 10000 & 3048 & 0.708 & 395 & 388 & 451 & 203.2 & 199.7 & 232.3 \\
\hline 20000 & 6096 & 0.843 & 395 & 378 & 518 & 203.2 & 194.6 & 266.4 \\
\hline 21752 & 6610 & 0.870 & 395 & 376 & 531 & 203.2 & 193.7 & 273.1 \\
\hline 41010 & 12500 & 0.870 & 281 & 278 & 499 & 144.3 & 143.1 & 256.7 \\
\hline
\end{tabular}

Figure 4: Design speeds of the iGREEN aircraft

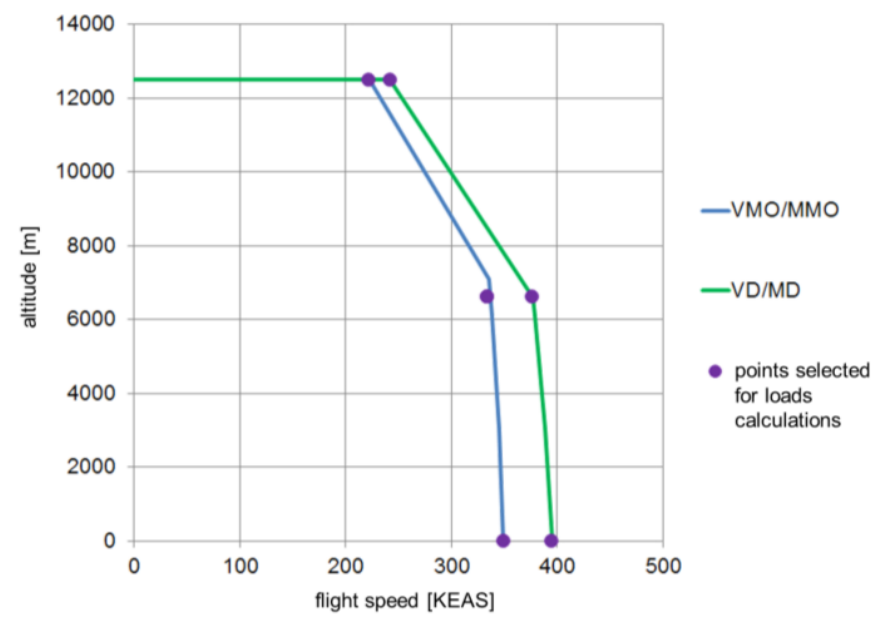

Figure 5: Flight envelope for loads and aeroelastic calculations of the iGREEN aircraft

\subsection{Structural model for aeroelastic analysis}

For the calculations of gust loads and the flutter analysis, a structural model of the complete aircraft suited for dynamic analysis is required. The full aircraft model of iGREEN was set up component wise: FE models of wings, horizontal and vertical stabilizer and fuselage were modelled separately using ModGen, and assembled afterwards. In a second step, the structure was sized using the selected load cases.

The wing-like structures (main wing, empennage) are modelled using shell elements, while the fuselage is represented as a beam structure. For the wing-like structures, the design concept of a wing box is defined. This is done by positioning of spars at distinct distances from leading and trailing edge. Ribs are defined between front and rear spar. Besides the ribs in the root region and at the tip, the ribs of the wing are defined perpendicular to the rear spar. Stringers are defined along the span. They are represented as beam elements, following the isoparametric discretization of the skin. Furthermore, a load reference axis is defined along the span at about $40 \%$ chord, close to the presumed elastic axis. In total six degrees of freedom of three selected border nodes per rib are used to define the elastic characteristics of the structural wing box at the nodes of the load reference axis. 
A representative stiffness and mass distribution for the fuselage is obtained using a mixed physical and analytical approach, based on geometric parameters like fuselage cross section, assumed average shell thickness, and the position of the wing along the fuselage. The resulting values are scaled with factors derived from existing models of fuselage structures.

The engine is represented as a rigid body with realistic mass and inertia. Of special interest were the inertial properties of the rotating engine parts. In the iGREEN project, a realistic assumption of the gyroscopic terms of the running engine has thus been determined. The engine is mounted to the fuselage using spring elements with representative stiffness.

The component models have been combined with special consideration towards the joint definition between wings and fuselage, empennage and fuselage, and engines and fuselage. Figure 7 shows the assembled aircraft finite element model.

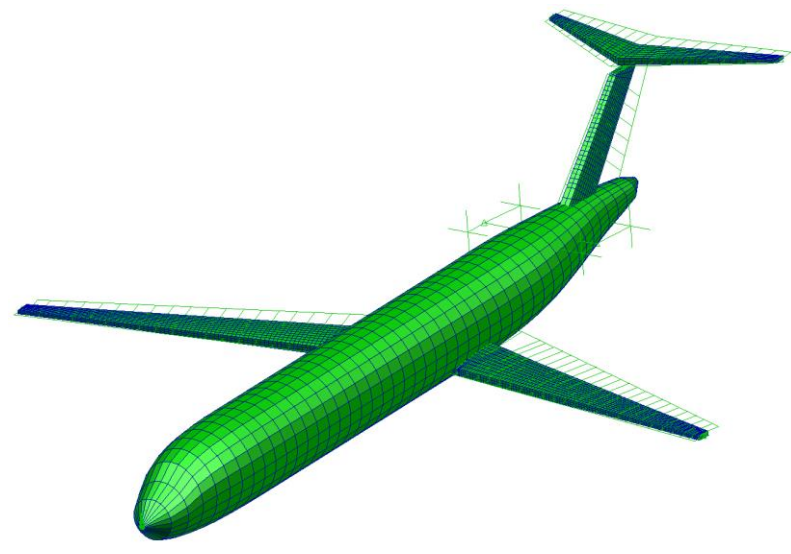

Figure 6: Structural model of the iGREEN configuration

\subsection{Mass model}

The mass model consists of several contributions. The structural mass of wings and empennage is taken from the MONA process. Here, the weight of the load-carrying parts is an output of the sizing process. As the finite element models use mainly shell elements, the mass moments of inertia can also be well represented. Masses for leading and trailing edge components of the wing, as well as for systems and for control surfaces, are taken from statistics-based data. Masses in the fuselage (systems, payload, cabin interior, passengers) are taken into consideration for various mass cases. Here, values estimated from PrADO have been used and processed into a mass model. Additionally, fuel mass for all relevant mass cases is calculated from the parameterized ModGen model. For the mass of high lift systems, empirical data are also available; however, the forward-swept wing is outside the range of existing data sets, so the mass of the high lift system was derived from a finite element model of a high lift system which was set up independently, using the separate model generator ELWIS of DLR Institute of Air Transportation Systems [34]. Figure 8 gives a representation of the mass model of the aircraft.

For a representative amount of analyses, a variety of mass cases have to be investigated. Figure 9 shows the set of configurations defined for the design process. The mass cases are derived from preliminary PrADO calculations, as well as from configurations defined when the manoeuvre loads and gust loads definitions are taken into consideration. Note that, to be conservative, some of those points will have extreme forward or backward center of gravity (CG) positions, which are possibly located outside the regular operational envelope of the aircraft. 


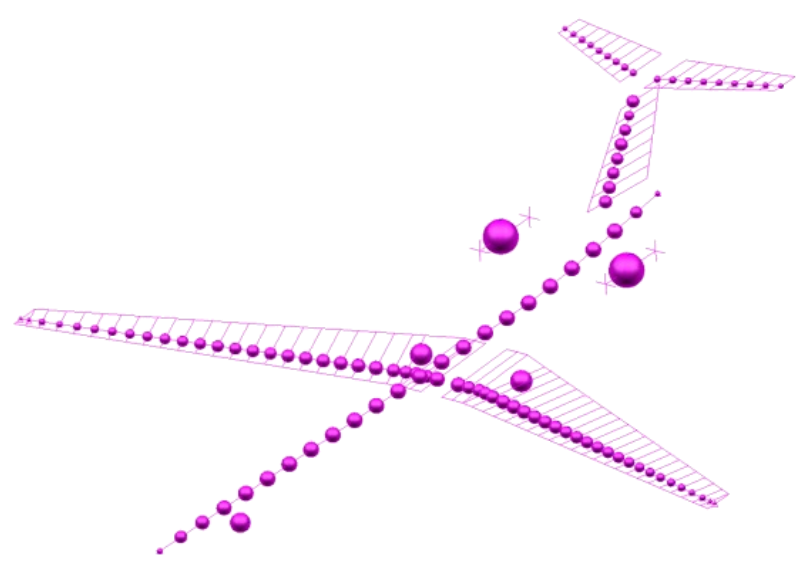

Figure 7: Selected mass model of the iGREEN configuration

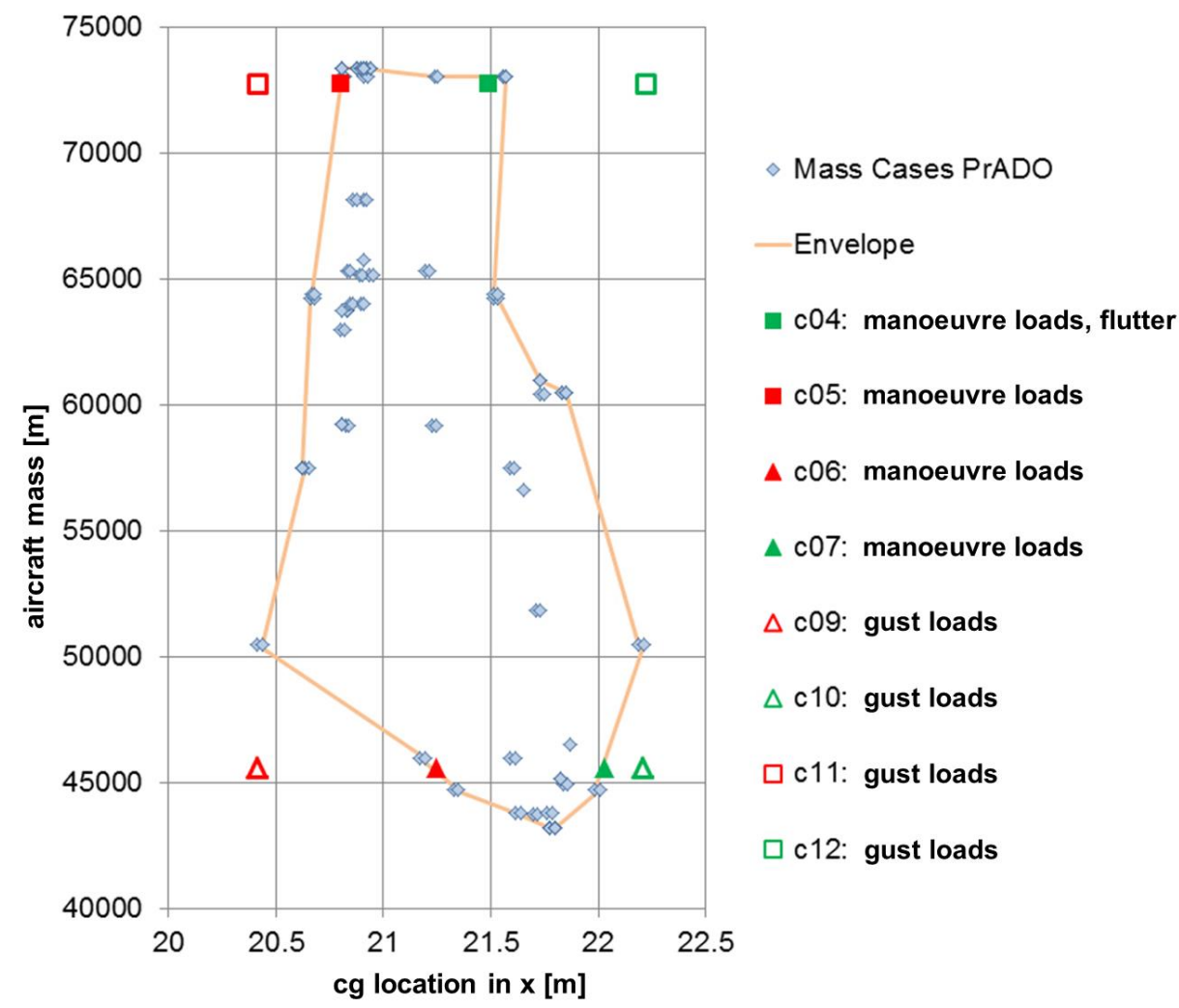

Figure 8: Mass configurations for loads and flutter analysis

\subsection{Aerodynamic model}

In the MONA process, the sizing of the structural elements is performed using NASTRAN solutions, and a doublet-lattice method (DLM) model of wing and empennage is part of the model generation process, see Fig. 10, top. As the aerodynamic forces, either the native NASTRAN DLM formulation can be used, or external forces can be supplied in the form of NASTRAN force cards. The use of NASTRAN internal DLM for sizing has the added advantage that trimmed solutions in the sizing process, i.e., the feedback of structural design on wing deflections, and thus on exact loads, can be introduced straight forward. 

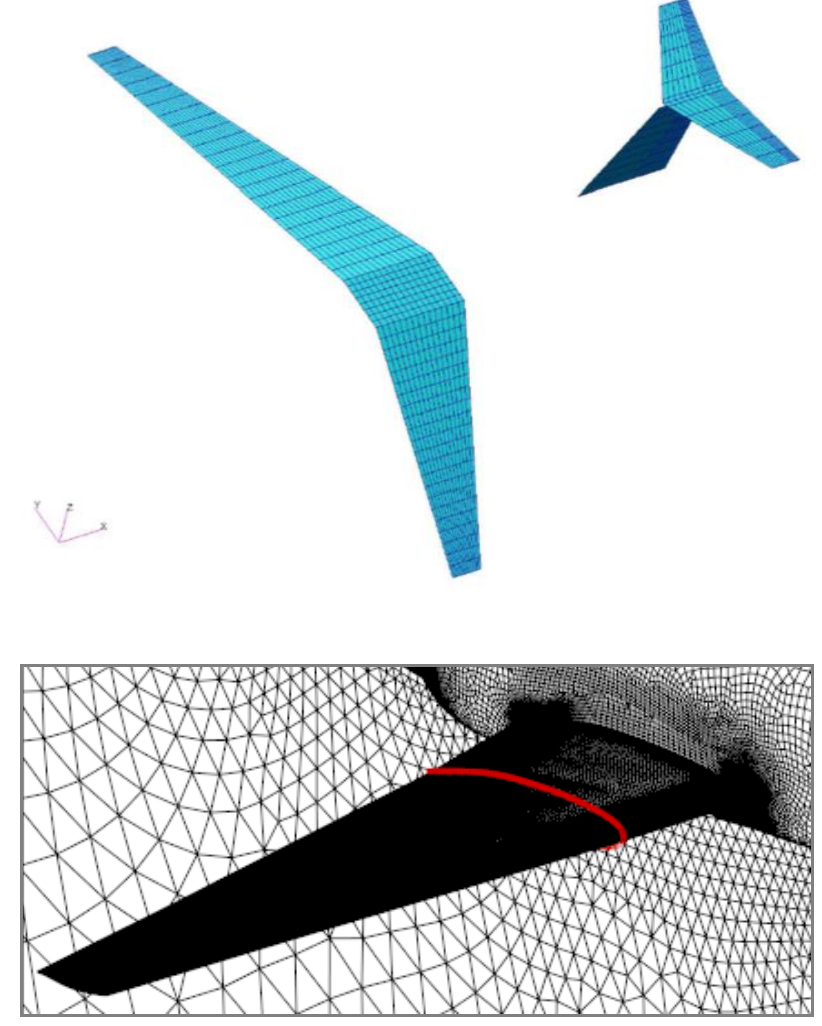

Figure 9: DLM and CFD models from model generation process

However, the process is capable of using results from CFD analyses, e.g., where the introduction of transonic effects is necessary. This can be done using the interfaces for corrections of NASTRAN DLM, i.e., by modification of the steady component of the aerodynamic influence coefficient (AIC) matrices, or by replacing strip-wise values for lift and moment on the wing profile by results taken from CFD calculations. Alternatively, lift distributions from CFD results can be introduced when the aerodynamic forces are exported in the form of NASTRAN force cards.

As the ModGen model generation process is geometry based, the export of an IGES surface for CFD mesh generation is possible, see Fig. 10, bottom [35]. Fully coupled aeroelastic simulations for selected points have been performed using the DLR TAU code in Euler and RANS mode. The forces on the CFD mesh are transferred to the 2D DLM discretisation. Figure 11 shows comparisons of the pressure difference between upper and lower sides of the iGREEN wing for a cruise case at Ma $=0.8$ at an altitude of $H=7,010 \mathrm{~m}$. For use in the iGREEN project, the forces have been saved as NASTRAN force cards; AIC correction is part of other activities at the DLR Institute of Aeroelasticity.

CFD results - either for direct usage or for AIC correction - are produced for a few selected Mach numbers only. The generation of a full set of CFD data was well beyond the scope of the project. Thus, only a small number of load distributions have been generated during the iGREEN project, with the goal to evaluate the physical offset in loads resulting from the use of DLM when compared to higher fidelity methods. The sizing process used for the iGREEN aircraft has mainly been based on uncorrected DLM aerodynamics. 


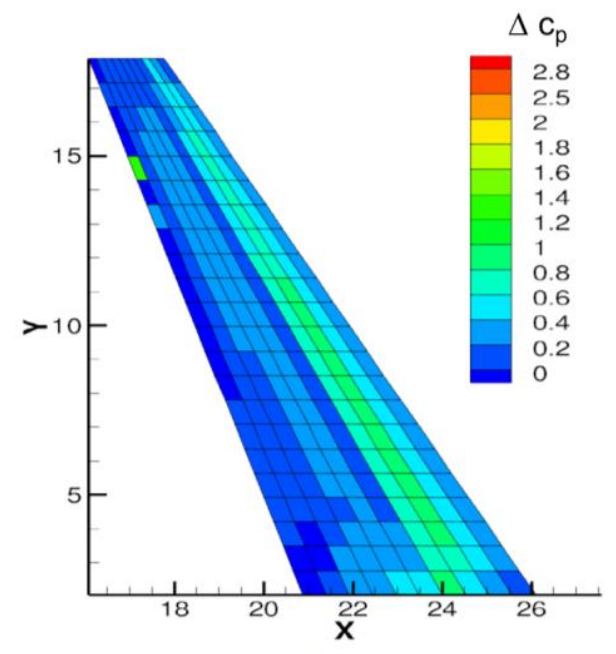

(a) Euler

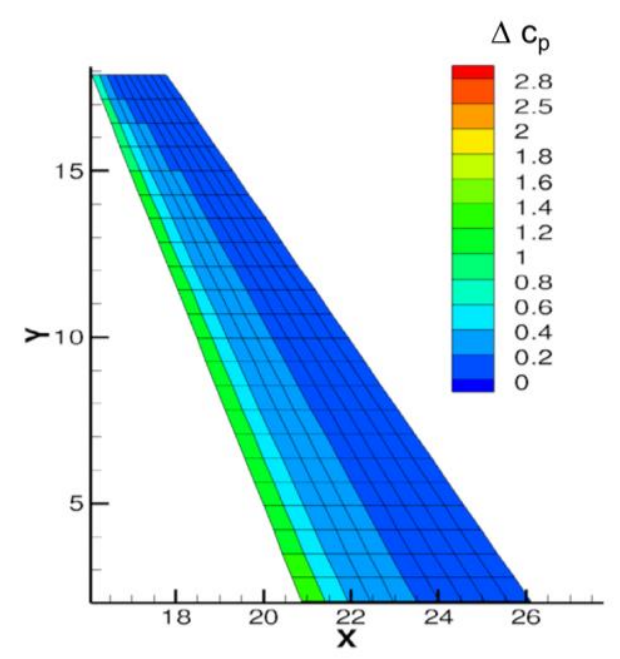

(b) DLM

Figure 10: Comparison of CFD (Euler) and DLM results

\subsection{Loads and Sizing}

The iterative loads and sizing process MONA has been applied to the iGREEN configuration. Loads calculation steps and sizing steps are performed in loops, until the structural weight of the components converges. The starting point of the iteration is a preliminary structural sizing according to text book approaches. During the design process, it could be shown that the final converged sizing result was reached independently from the starting point.

A complete set of sizing load cases includes several dozen different load cases including manoeuvers, gusts, landing impact, etc., to cover the maximum loads on all components, plus several hundreds, if not thousand additional load cases against which the validity of the resulting structure has to be checked. However, the aim of the current exercise is to get a good mass estimate for the aircraft configuration, and to derive a finite element model representing the global aeroelastic behaviour of the aircraft (the so-called Global FEM, or GFEM). According to experience, a small set of carefully selected loads cases will already give very good results with respect to mass estimation and GFEM generation.

In the sizing process, only loads from static manoeuvres from selected points of the flight envelope were used. Symmetric manoeuvres were mainly used to size the wings, while anti-symmetric manoeuvres were defined for the sizing of the fin. Loads for the landing impact were calculated using handbook methods. Mass and stiffness of the fuselage beam were kept constant during the sizing runs.

The loop starts with loads on the rigid aircraft. The computed loads are transferred component wise into cut loads and are plotted in the form of a loads envelope for shear force, bending moment and torsional moment, which are then used in the initial MONA sizing step. For those component models, mass data (centre of gravity, mass, mass moments of inertia) are calculated using NASTRAN, afterwards all mass data are combined in the so-called master nodes of the finite element model inside ModGen.

After the initial sizing, the manoeuvres are repeated including a preceding calculation of the static equilibrium (a trim calculation in NASTRAN lingo). The sizing process is repeated with the new load set. For the current aircraft design, one step with the rigid aircraft plus four loops with the elastic aircraft leads to a converged structural sizing. It is interesting to note that the mass of the primary structure does not change much with the iterations, but a shift of skin thickness from the inner to the outer wing can be observed during the iterations, see Fig. 12. 


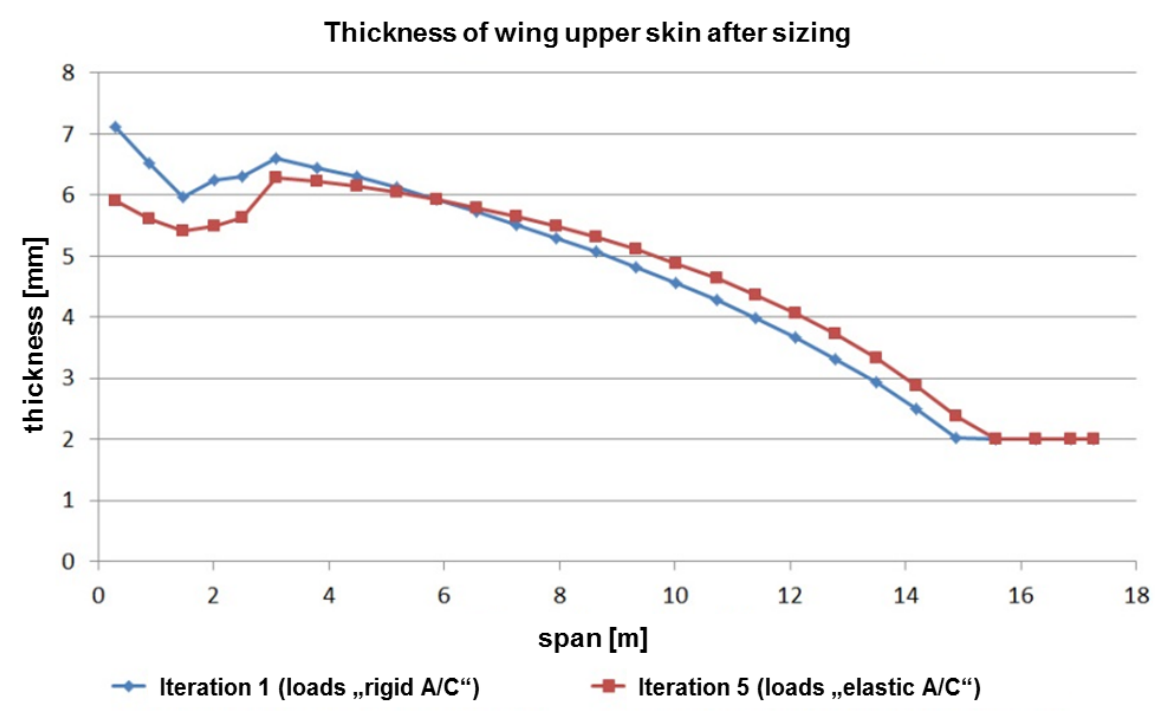

Figure 11: Wing skin thickness convergence

For the wings and the horizontal stabilizer, the sizing process resulted in realistic mass and stiffness distributions. For the fin, however, the process leads to an unrealistically low structural weight, probably because the selected load cases did not cover all relevant areas. Thus, the final structure was modified by stringer and spar dimensions taken from aircraft of comparable configuration.

Figure 13 shows how different sections of the wing are sized by different load cases. For the shear force of the inner wing section, ground handling load cases are most critical (which play no role for the bending moment), whereas the middle of the wing is sized by a high-g-case $\left(n_{z}=2.67\right)$ at high altitude, the outer wing by a manoeuver at medium altitude and $n_{\mathrm{z}}=2.5$.
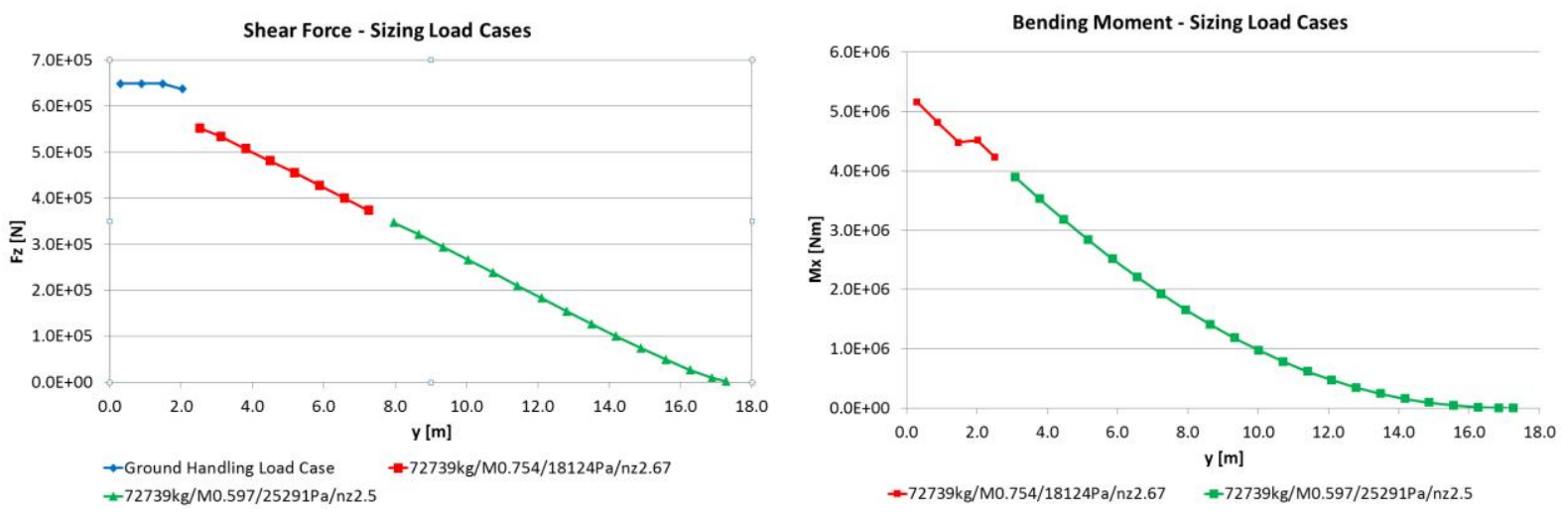

Figure 12: Resulting maximum cut loads over wing span from loads analysis

It should be noted that, while not every step in the model generation is fully automated, the setup of the simulation models has a high degree of parameterization and automation. Thus, after changes in the configuration, the sizing and analysis runs can be repeated very quickly.

One verification check of the resulting aircraft model is the analysis of the eigenmodes, i.e., the natural frequencies and the mode shapes, see Fig. 14. The resulting mode shapes are realistic and the frequencies are comparable to those of other aircraft of the same size. 


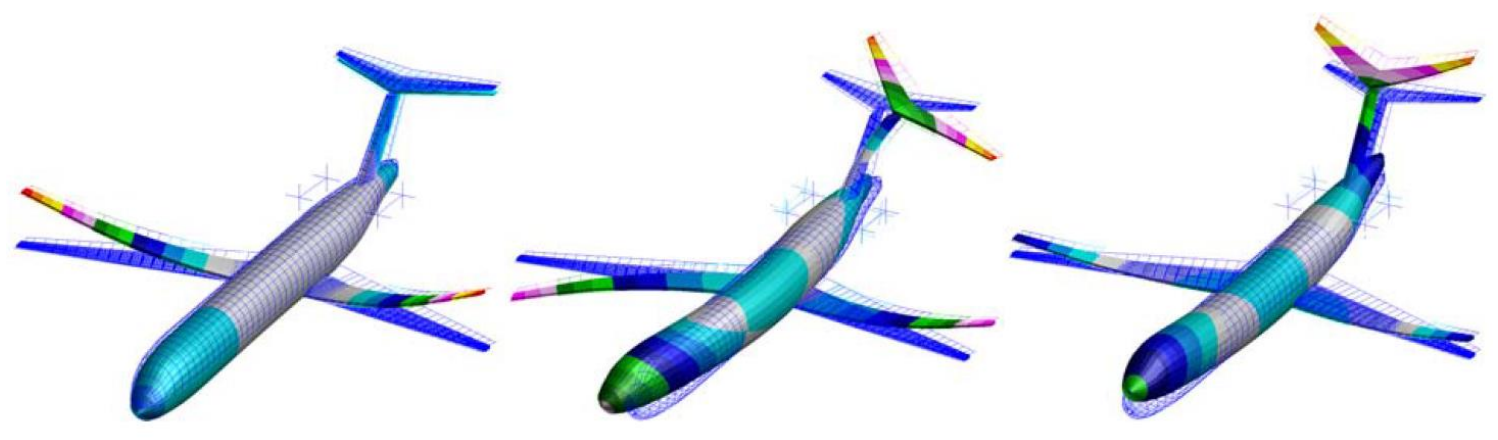

Figure $13: 1^{\text {st }}, 3^{\text {rd }}, 5^{\text {th }}$ eigenmodes of iGREEN configuration

Another check is the comparison of the resulting structural masses with other aircraft and results from classical pre-design mass estimation. In both cases, the masses obtained for the iGREEN configuration with the model generation and sizing process are reasonable.

At this point, an aircraft model with realistic dynamic properties is available for aeroelastic investigations.

\section{AEROELASTIC ANALYSES ON THE REFERENCE CONFIGURATION}

\subsection{Divergence analysis}

For forward-swept aircraft, divergence is a critical issue. Thus, for the iGREEN configuration a divergence analysis was performed in MSC.NASTRAN, regarding an isolated right wing, and using uncorrected DLM aerodynamics. In Fig. 15, analysis results for different Mach numbers are given, showing that the divergence speed is outside the aeroelastic stability envelope, but with a smaller margin as for most classical backwardswept wings.

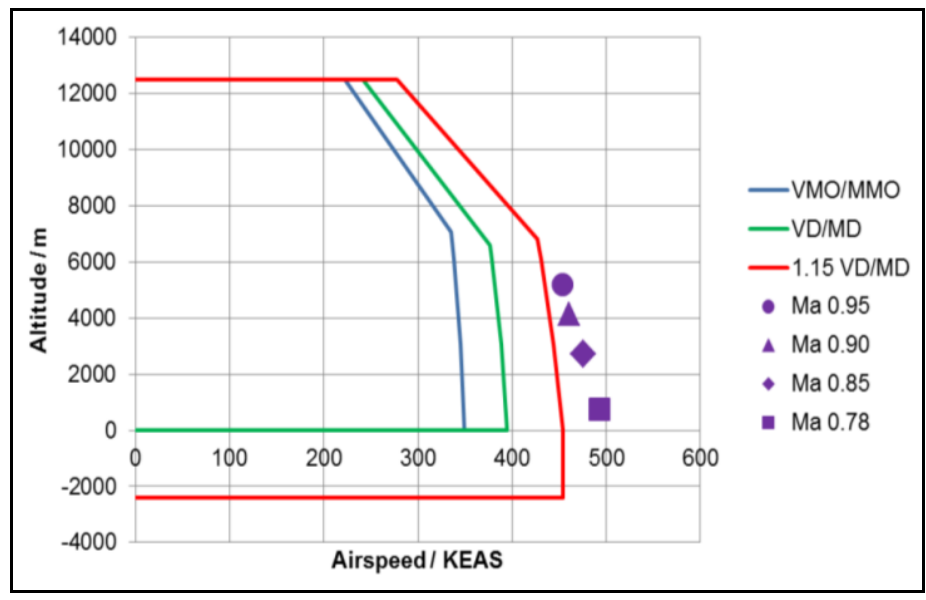

Figure 14: Divergence analysis results vs. aeroelastic stability envelope

\subsection{Gust loads analysis}

The output of the iGREEN reference configuration design was subjected to a subsequent gust loads analysis. For this purpose, models with extreme forward and backward CG positions and maximum moment of inertia as given in Fig. 9 were provided to obtain conservative gust loads results. The analysis points were selected according to the regulations CS-25/FAR-25. Using input parameters for gust lengths and amplitudes derived from those requirements, time domain simulations for discrete gusts were performed. The regulations specify the so-called "1-cos-gust" for dynamic analysis. Gust lengths have to vary between 9 and $107 \mathrm{~m}$, and a sufficient 
number of gust simulations (10-20 gust lengths seem to be acceptable) have to be performed to identify potential critical gusts which are relevant for structural sizing. Following the aviation regulations, the reference gust velocity to be simulated in the gust analysis is $17.07 \mathrm{~m} / \mathrm{s}(56 \mathrm{ft} / \mathrm{s})$ EAS at airplane speeds between $V_{\mathrm{B}}$ and $V_{\mathrm{C}}$. Due to minor vertical atmospheric disturbances at higher flight regimes, the reference gust velocity reduces linearly from $17.07 \mathrm{~m} / \mathrm{s}(56 \mathrm{ft} / \mathrm{s})$ EAS at sea level flight to $13.41 \mathrm{~m} / \mathrm{s}(44 \mathrm{ft} / \mathrm{s})$ EAS at 4,572 m $(15,000 \mathrm{ft})$ and further to $6.36 \mathrm{~m} / \mathrm{s}(20.86 \mathrm{ft} / \mathrm{s})$ EAS at $18,288 \mathrm{~m}(60,000 \mathrm{ft})$.

The results given in Fig. 16 are the time domain loads for forces and moments inside the flight envelope, according to minimum and maximum gust length. For the given case, the maximum load factor was obtained for the long wave gust whereas the maximum pitch acceleration is related to the short gust length. The resulting correlated loads, i.e., the relationship between the time-dependent shear force and torsional moment, are given in Fig. 17. Out of those results, a convex hull can be defined to identify the maximum loading during gust excitation.

\section{Aircraft heave, cruise, $M a=0.78 ; u_{\infty}=236.475 \mathrm{~m} / \mathrm{s} ; \rho=0.458 \mathrm{~kg} / \mathrm{m}^{3}$}
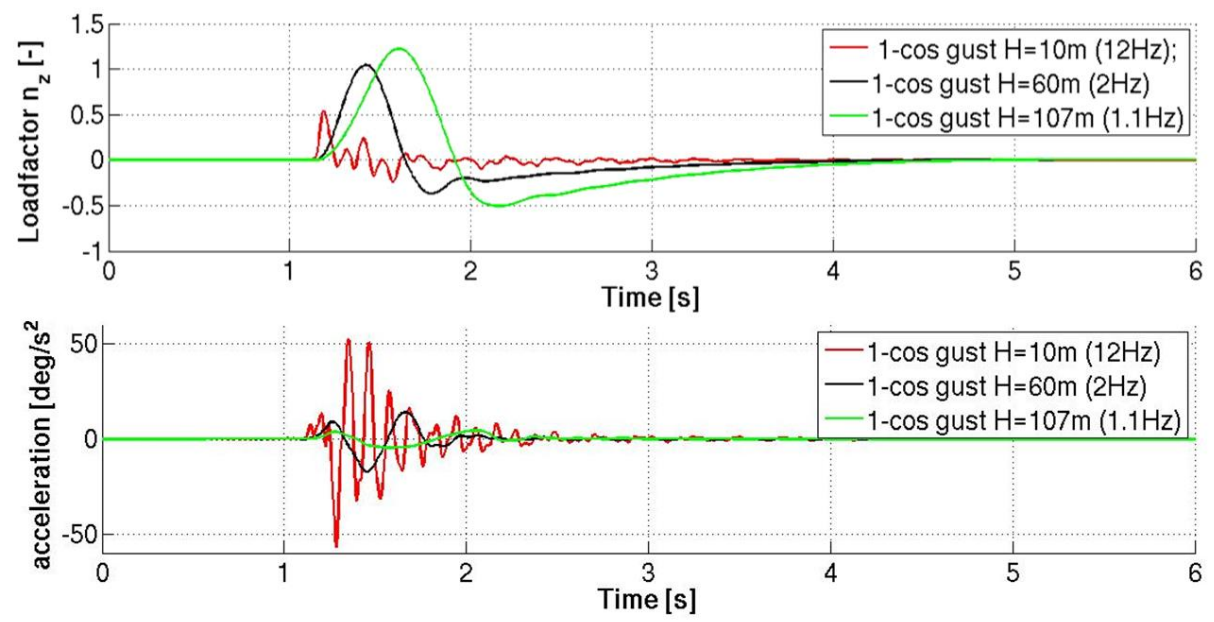

Figure 15: Gust analysis: load factor and acceleration for aircraft heave at cruise

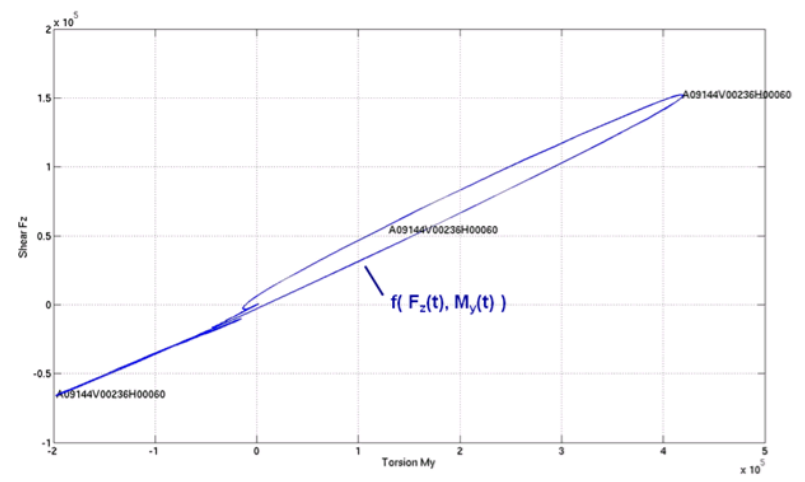

Figure 16: Loads at the wing root for a given time domain simulation

For this purpose, results for shear force over torsional moment, or bending moment over torsional moment, being determined from the time domain results at the wing root, are combined in a common diagram. These so-called balanced loads, i.e., the overall sum of inertial, aerodynamic and external loads, are computed separately for each flight point at different structural monitoring points on the wing and are later combined with their specific 1-g level flight case. Combining the values, an envelope over all cases is constructed, see Fig. 18. These correlated loads represent the static relation of loads inside the flight envelope and can be used for structural 
design. In the iGREEN project, however, the gust loads analysis has only been used as a post-processing step on the existing aircraft structure.

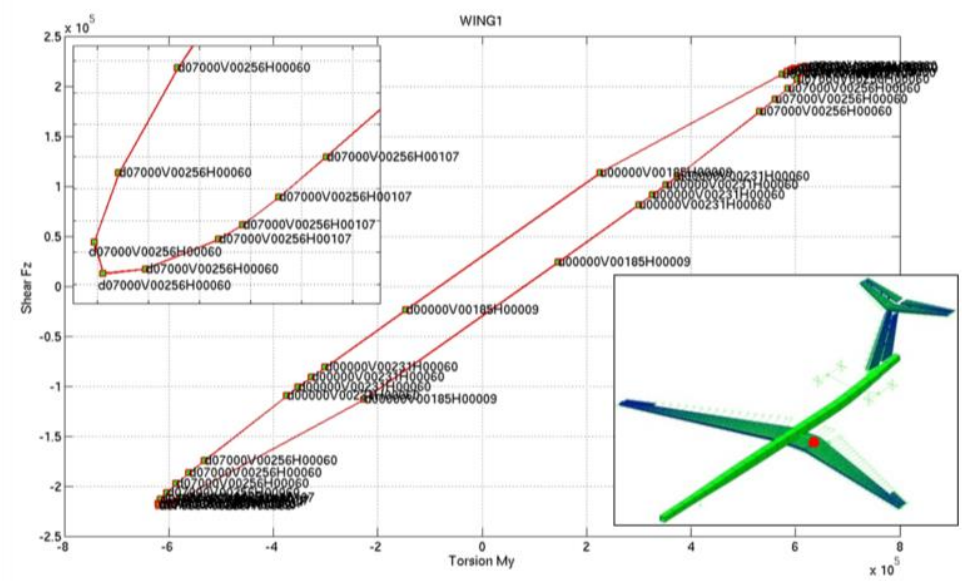

Figure 17: Correlated loads at the wing root

Over the aircraft, different parts of the structure receive their maximum loads from different loads cases. Figure 19 gives examples for several components with the respective gust load cases, indicating which gust has been the most critical for a certain component.

\begin{tabular}{|c|c|c|c|c|c|c|}
\hline Load Case & Wing root & Mid-Wing & Wing tip & $\begin{array}{l}\text { Horizontal } \\
\text { stab. root }\end{array}$ & $\begin{array}{l}\text { Horizontal } \\
\text { stab. tip }\end{array}$ & $\begin{array}{l}\text { Fuselage - } \\
\text { T-tail }\end{array}$ \\
\hline $\begin{array}{l}\text { MSL, } 124 \text { TAS, } \\
\text { H } 10 \mathrm{~m}\end{array}$ & & & & & & $x$ \\
\hline $\begin{array}{l}\text { MSL, } 124 \text { TAS, } \\
\text { H } 107 \mathrm{~m}\end{array}$ & & & $x$ & $\mathrm{x}$ & & \\
\hline $\begin{array}{l}\text { MSL, } 144 \text { TAS, } \\
\text { H } 10 \mathrm{~m}\end{array}$ & & & $x$ & $\mathrm{x}$ & & \\
\hline $\begin{array}{l}\text { MSL, } 144 \text { TAS, } \\
\text { H } 60 \mathrm{~m}\end{array}$ & & & $x$ & $x$ & & \\
\hline $\begin{array}{l}\text { MSL, } 144 \text { TAS, } \\
\text { H } 107 \mathrm{~m}\end{array}$ & $\mathrm{x}$ & $\mathrm{x}$ & & & $x$ & \\
\hline $\begin{array}{l}4572 \mathrm{~m}, 182 \text { TAS, } \\
\text { H } 10 \mathrm{~m}\end{array}$ & & & & $x$ & $x$ & $x$ \\
\hline $\begin{array}{l}9144 \mathrm{~m}, 236 \text { TAS, } \\
\text { H } 10 \mathrm{~m}\end{array}$ & & & & $x$ & $x$ & $x$ \\
\hline $\begin{array}{l}9144 \mathrm{~m}, 236 \mathrm{TAS}, \\
\mathrm{H} 60 \mathrm{~m}\end{array}$ & $\mathrm{x}$ & $x$ & $x$ & & & \\
\hline $\begin{array}{l}9144 \mathrm{~m}, 236 \text { TAS, } \\
\mathrm{H} 107 \mathrm{~m}\end{array}$ & $x$ & 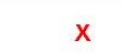 & & & & \\
\hline
\end{tabular}

Figure 18: Maximum loads at aircraft stations from gust load analysis

\subsection{Flutter analysis}

The quantification of the effects of engine thrust vector and of gyroscopic effects on aeroelastic stability had been subject of an iGREEN work package. The structural models of the iGREEN configuration have therefore been used for flutter analysis, with a special focus on the investigation of those effects.

The gyroscopic coupling terms lead to skew-symmetric terms in the damping matrix. The thrust vector leads to phase shifts resulting from the motion of the engine with respect to the wing, and can be represented by a modification of the stiffness matrix. The resulting equation of motion is non-conservative, and even without aerodynamic forces leads to complex eigenvalues and a potentially unstable system. Two alternatives for the numerical analysis of an aircraft with a rotating engine in standard analysis software are possible:

First, the eigenvalue analysis can be performed completely in NASTRAN for the full aircraft, resulting directly in complex modes. However, a variation of the engine rotational speed would require a full new analysis for 
each engine setting, always with the full aircraft model. The generalized air forces would have to be recalculated for each complex mode and for each rotational speed.

In a second approach, an eigenvalue analysis can be performed for an aircraft model with engines off, leading to real eigenvalues and modes, and the gyroscopic forms are added to the results by means of a modal correction. This approach has the advantage that parameter variations can be performed in modal space, i.e., only the required modal degrees of freedom are included. Furthermore, the unsteady aerodynamic matrices only have to be calculated once. However, the correction terms have to be determined in separate analyses.

In the iGREEN project, a process has been developed to apply the second approach, i.e., to work via a modal correction with complex values. Basis for the analysis models are linearized mass and stiffness matrices from standard FEM eigenvalue analyses; in a further step, the coupling terms are generated in separate tools. The resulting equation of motion is combined in ZAERO, where also the subsequent stability analysis is performed. Furthermore, the DLM model of the original design process has been manually extended to include a fuselage and engine nacelles.

For the flutter analyses of the configuration, the data for engine thrust as well as for moments of inertia of the rotating engine parts have been estimated for a CFM56-5B1-type engine. Parameter variations for pylon stiffness and CG position of the engines with respect to the attachment were performed.

The results of the flutter calculations for the unmodified reference configuration, engine off, are given in Fig. 20. The flutter boundary is well beyond the required limit. Lowest flutter mode is an anti-symmetric fin rock with fuselage torsion, see Fig. 21, left. The second flutter point corresponds to an aeroelastic instability of the horizontal stabilizer (not shown), while the third flutter mode is symmetric wing flutter, Fig. 21, right.
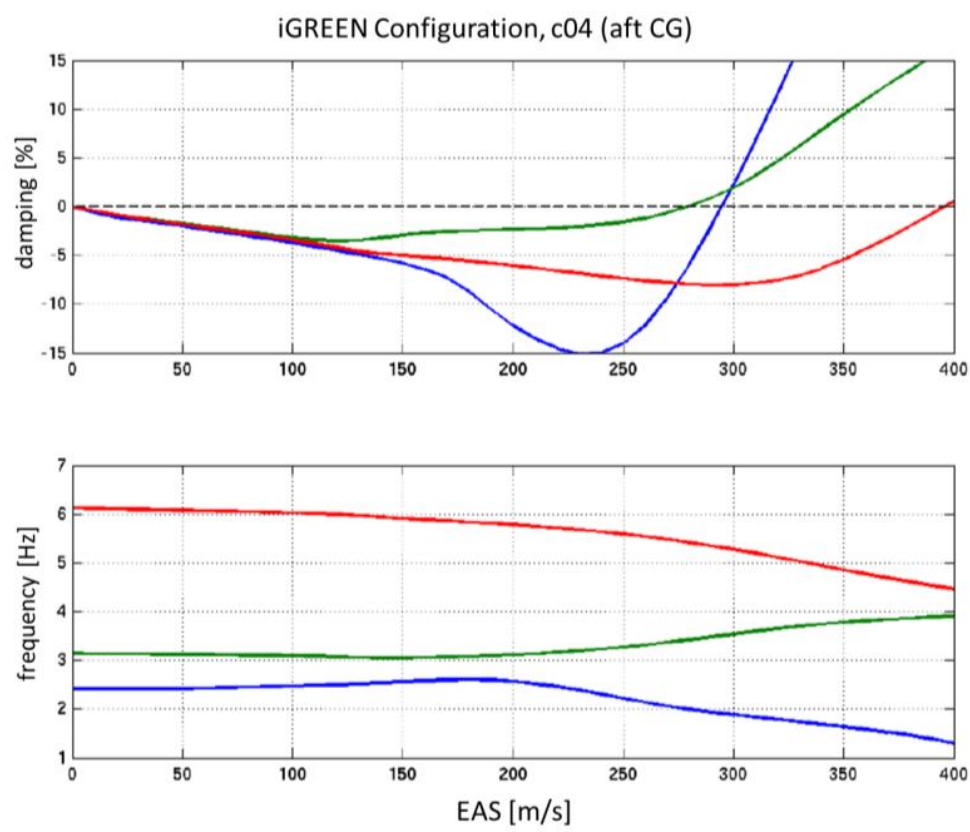

Figure 19: Flutter analysis of iGREEN reference configuration

As a comparison, analyses for aircraft with running engines (gyroscopic terms and thrust vector included) have been performed. It can be stated that the impact of these effects on the global flutter behaviour is secondary for the regarded configuration. The effects become more pronounced as the rotational components of the engines begin to influence the local vibratory motion of the engine. For the iGREEN configuration, only small effects on the flutter frequencies can be shown, and no major shift of the stability boundary is visible for the current aircraft configuration. This is mainly due to the fact that the rear-mounted engines have only a small lever arm between engine and fuselage, so the non-conservative forces have no great influence on the mode shapes. Additionally, the engine attachment, i.e., the pylon, is rather stiff, allowing only little independent elastic motion of the engine. 


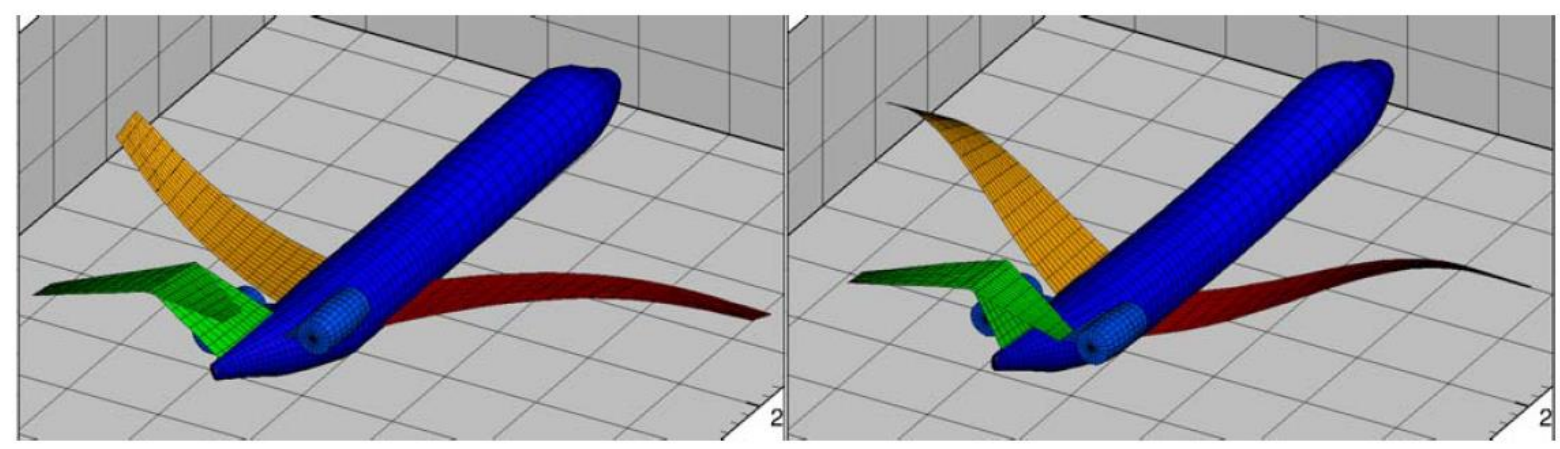

Figure 20: Flutter modes of iGREEN configuration

\subsection{Control surface layout}

A classical task for static aeroelastic analysis is the determination of control surface efficiency. This is especially interesting for a forward-swept wing, as the bending-torsion coupling usually increases aileron efficiency when compared to a wing with the same backward sweep angle. Investigations of control surface layout have been undertaken on the LamAiR wing, a wing of the same planform as the iGREEN wing, but defined with a laminate structure instead of isotropic material, see Sect. 2.1.

As part of the LamAiR project, sensitivity studies of the aileron size were performed to estimate the aileron efficiency and reversal behaviour for the CFRP wing structure. The initial size and position was similar to that of conventional short- to medium-range aircraft of the A320 class. The analyses of the aileron efficiency were performed based on flight load cases at the corners of the aeroelastic stability envelope, see Fig. 15, in Sect. 3.1 above. The design variations investigated in the project included variations of aileron span and aileron chord. A measure of aileron effectiveness is the aircraft roll rate, where a negative roll rate would indicate aileron reversal. For none of the regarded design variations, aileron reversal could be identified. Sufficient to good roll rates can be observed for all variants.

Based on these results a cross study of both mid-size aileron variations was performed (12\% flap length and $26 \%$ flap chord depth). A comparison of the results between the initial reference aileron layout and the modified one is shown in Fig. 22. The selected modified aileron shows decreasing aileron efficiency with respect to the initial design, but still sufficient roll rates for the considered flight cases. Figure 22, bottom left, shows the details of the aerodynamic DLM model at the wing tip, comparing the size of the reference aileron (red) to the modified aileron (yellow). The roll requirements are still fully met with an aileron approximately $30 \%$ smaller than the original proposal.

The study could thus show that the forward-swept wing has the potential of smaller control surfaces. This is especially interesting from the design point of view, as the requirements for a wing allowing natural laminar flow may significantly limit the potential for high lift devices at the leading edge, and a smaller aileron might allow the use of enlarged high lift devices on the wing trailing edge. 

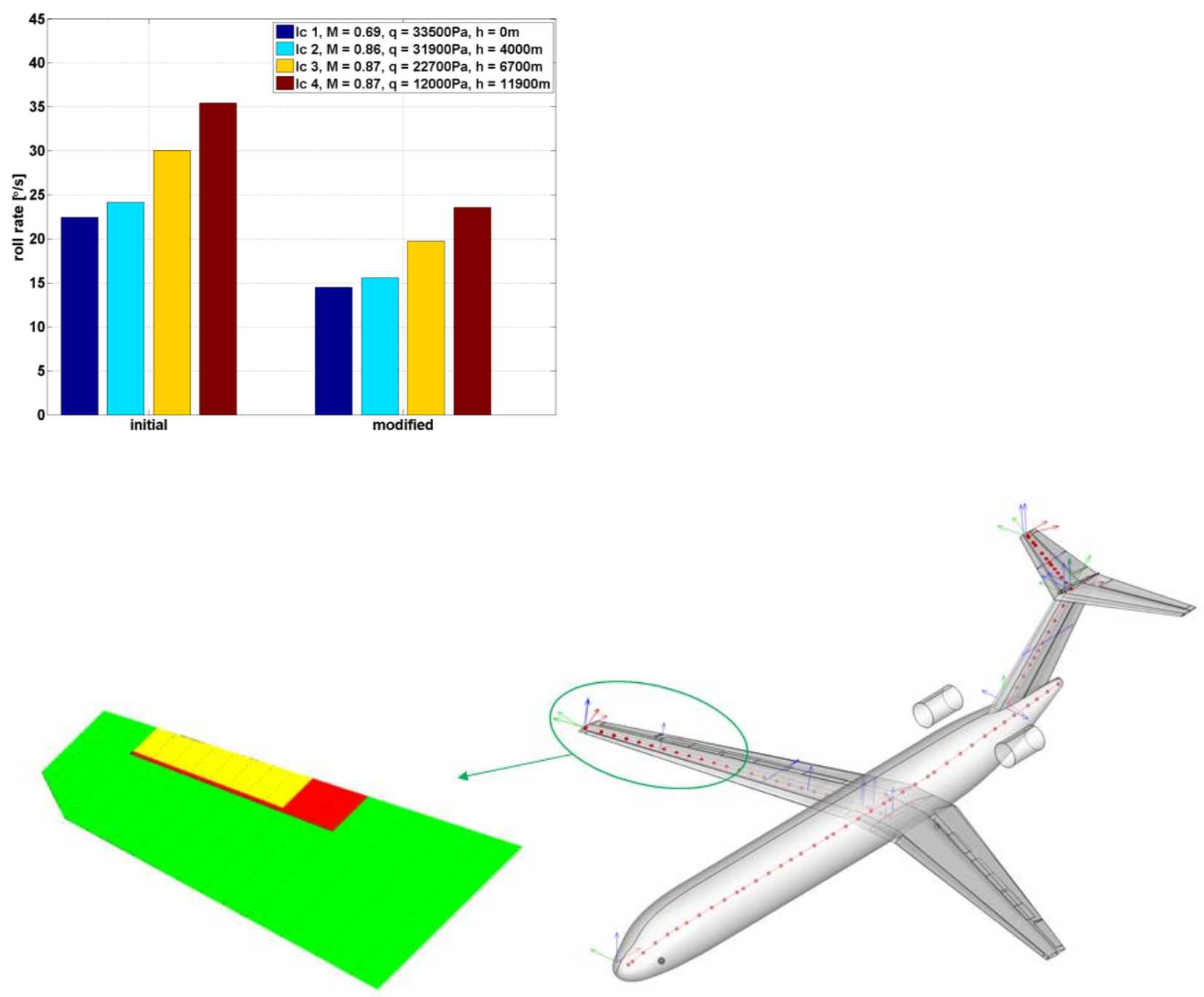

Figure 21: Roll rates for an initial and a modified aileron (top), and aerodynamic model of the wing tipwith inital and final aileron size (bottom)

\section{CONCLUSIONS}

In the course of the DLR iGREEN project, a reference aircraft model has been built up. The configuration has several characteristics relevant for a fuel-efficient aircraft, especially forward-swept wings and rear-mounted engines, beneficial for increased natural laminar flow on the wing and thus reduced drag. Design aspects related to aeroelastic effects have been investigated, taking advantage of a parameterised modelling approach for aircraft structure and aerodynamics. A model representing the global aeroelastic static and dynamic effects was created.

Future work continues in the DLR project ALLEGRA ("AeroeLastic stability and Loads prediction for Enhanced GReen Aircraft", 2012-2015). The ALLEGRA reference aircraft is a further development of the iGREEN configuration, with a composite wing. The activities in the project include structural optimization (Aeroelastic Tailoring), the development of improved gust loads analyses based on CFD results, and an investigation of load reduction techniques. 
Note: This is a post-peer-review, pre-copyedit version of an article published in the CEAS Aeronautical Journal. The final authenticated version is available online at: https://doi.org/10.1007/s13272-014-0117-0.

\section{REFERENCES}

[1] Mai, H., Hebler, A.: Aeroelasticity of a laminar wing. Proc. IFASD 2011 - 15th International Forum on Aeroelasticity and Structural Dynamics, 26 - 30 June 2011, Paris, France (2011)

[2] Fehrs, M.: Influence of Transitional Flows at Transonic Mach Numbers on the Flutter Speed of a Laminar Airfoil. Proc. IFASD 2013 - 16th International Forum on Aeroelasticity and Structural Dynamics, 24 - 27 June 2013, Bristol, UK (2013)

[3] Schmidt, H., Neumann, J., Mai, H.: Analysis of forced response in a wind tunnel based on doublet-lattice method. CEAS Aeronaut. J. 2, 271-277. Springer. DOI: [10.1007/s13272-011-0017-5] (2011)

[4] Neumann, J., Mai, H.: Gust response: Simulation of an aeroelastic experiment by a fluid-structure interaction method. J. Fluid Struct. 38(1), 290-302. Elsevier (2013)

[5] Seitz, A., Kruse, M., Wunderlich, T., Bold, J., Heinrich, L.: The DLR Project LamAiR: Design of a NLF Forward Swept Wing for Short and Medium Range Transport Application. 29th AIAA Applied Aerodynamics Conference, 27.-30. Juni 2011, Hawaii, USA (2011)

[6] Kruse, M., Wunderlich, T.F., Heinrich, L.: A Conceptual Study of a Transonic NLF Transport Aircraft with Forward Swept Wings. 30th AIAA Applied Aerodynamics Conference, 25. - 28. Jun 2012, New Orleans, USA (2012)

[7] Heinze, W., Österheld, C.M., Horst, P.: Multidisziplinäres Flugzeugentwurfsverfahren PrADO Programmentwurf und Anwendung im Rahmen von Flugzeug-Konzeptstudien. Jahrbuch der DGLRJahrestagung 2001, Hamburg, Germany (2001)

[8] Krone, N. J. Jr.: Divergence Elimination with Advanced Composites". AIAA Paper 75-1009 (1975)

[9] Weisshaar, T. A.: Divergence of Forward Swept Composite Wings," J. Aircr. 17, $442-448$ (1980)

[10] Weisshaar, T.A.: Aeroelastic Tailoring of Forward Swept Composite Wings. J. Aircr. 18 (8), 669-676 (1981)

[11] Spacht, G.: The Forward Swept Wing: A Unique Design Challenge. AIAA-80-1885. AlAA Aircraft Systems Meeting, August 4-6, 1980/Anaheim, California (1980)

[12] Lottati, I.: Flutter and Divergence Aeroelastic Characteristics for Composite Forward Swept Cantilevered Wing. J. Aircr. 22(11), 1001-1007 (1985)

[13] Librescu, L., Thangjithamt, S.: Analytical studies on static aeroelastic behavior of forward-swept composite wing structures. J. Aircr. 28(2), 151-157 (1991)

[14] Dillinger, J., Klimmek, T., Abdalla, M.M., Gürdal, Z.: Stiffness Optimization of Composite Wings with Aeroelastic Constraints. J. Aircr. 50 (4), 1159-1168 (2013). DOI: 10.2514/1.C032084. ISSN 0021-8669.

[15] Dillinger, J., Abdalla, M.M., Klimmek, T., Gürdal, Z.: Static aeroelastic stiffness optimization and investigation of forward swept composite wings. 10th World Congress on Structural and Multidisciplinary Optimization, 19-24 May 2013, Orlando, Florida, USA (2013)

[16] Hodges, D.: Nonlinear Composite Beam Theory, AIAA, Washington, D.C. (2006)

[17] Patil, M.J., Hodges, D.H., Cesnik, C. E. S.: Nonlinear aeroelasticity and flight dynamics of high-altitude long endurance aircraft. J. Aircr. 38(1), 88-94 (2001)

[18] Carrera, E., Petrolo, M.: Refined one-dimensional formulations for laminated structure analysis. AIAA J. 50(1) (2012)

[19] Petrolo, M.: Advanced 1D structural models for flutter analysis of lifting surfaces. Int J. Aeronaut. Space Sci. 13(2), 199-209 (2012). doi: 10.5139/IJASS.2012.13.2.199

[20] Cavagna, L., Ricci, S., Riccobene, L. (2009): A fast tool for structural sizing, aeroelastic analysis and optimization in aircraft conceptual design. AIAA 2009-2571. Proc. 50th AIAA/ASME/ASCE/AHS/ASC Structures, Structural Dynamics, and Materials Conference. 4 - 7 May 2009, Palm Springs, California. 
Note: This is a post-peer-review, pre-copyedit version of an article published in the CEAS Aeronautical Journal. The final authenticated version is available online at: https://doi.org/10.1007/s13272-014-0117-0.

[21] Cavagna, L., Ricci, S., Travaglini, L. (2011): NeoCASS: An integrated tool for structural sizing, aeroelastic analysis and MDO at conceptual design level. Prog. Aerosp. Sci. 47(8), 621-635 (2011)

[22] Patil, M.J., Hodges, D.H.: Flight dynamics of highly flexible flying wings. J. Aircr. 43(6), 1790-1798 (2006)

[23] Su, W., Zhang, J., Cesnik, C.E.S.: Correlations between UM/NAST nonlinear aeroelastic simulations and experiments of a cantilever slender wing. In: Proceedings of IFASD 2009-14th International Forum on Aeroelasticity and Structural Dynamics, 21-25 June 2009, Seattle, WA (USA) (2009)

[24] Frediani, A.: The Prandtl wing. In: Torenbeek, E., Deconinck, H. (eds.) VKI lecture series: "Innovative configurations and advanced concepts for future civil transport aircraft", 6-10 June, 2005, von Karman Institute, ISBN:2-930389-62-1 (2005)

[25] Bradley, M.K., Droney, C.K.: Subsonic ultra green aircraft research: phase I final report. NASA/CR-2011216847 (2011)

[26] Frota, J.: New aircraft concept research in NACRE - a five-year synthesis (2005-2010). Presentation. In: Aerodays 2011, 30 March-1 April 2011, Madrid, Spain (2011)

[27] Klimmek, T.: Parameterization of topology and geometry for the multidisciplinary optimization of wing structures. In: Proceedings of CEAS 2009-European Air and Space Conference, Manchester, United Kingdom, 26-29 October 2009 (2009)

[28] Klimmek, T.: Parametric set-up of a structural model for FERMAT configuration for aeroelastic and loads analysis. ASD J. 3(2), 31-49 (2014). doi: $10.3293 /$ asdj.2014.27

[29] Loads analysis VAMPzero: http://software.dlr.de/p/vampzero/home/. Accessed 29 May $2014^{1}$

[30] Krüger, W.R., Cumnuantip, S., Liersch, C.: Multidisciplinary conceptual design of a UCAV configuration. In: Proceedings of AVT-MP173. RTO/AVT Panel Workshop "Virtual Prototyping of Affordable Military Vehicles Using Advanced MDO”, 16-18 May 2011, Sophia, Bulgaria (2011)

[31] Kroll, N., Rossow, C.: Digital-X: DLR's way towards the virtual aircraft. In: NIA CFD Conference, 6-8. August 2012, Hampton Virginia, USA (2012)

[32] MSC.NASTRAN: http://www.mscsoftware.com/product/msc-nastran. Accessed 29 May 2014

[33] ZAERO: http://www.zonatech.com/ZAEROInformation.htm. Accessed 29 May 2014

[34] Dorbath, F., Nagel, B., Gollnick, V.: A Knowledge based approach for automated modelling of extended wing structures in preliminary aircraft design. In: Proceedings of DLRK 2011, 27-29 September 2011, Bremen, Deutschland (2011)

[35] Krüger, W.R., Klimmek, T., Liepelt, R., Schmidt, H., Waitz, S., Cumnuantip, S.: Design and aeroelastic assessment of a forward swept wing aircraft. In: Proceedings of IFASD 2013-16th International Forum on Aeroelasticity and Structural Dynamics, 24-26 June 2013, Bristol, UK (2013)

\footnotetext{
${ }^{1}$ link replaced by: https://www.dlr.de/lk/en/desktopdefault.aspx/tabid-8151/13975_read-35501/, Accessed 19 Sep 2019
} 